\title{
Noninvasive assessment of cardiac function during ventricular assist system support using 64-row multidetector computed tomographic angiography
}

\author{
Koji Takeda, MD, ${ }^{\mathrm{a}}$ Goro Matsumiya, MD, ${ }^{\mathrm{a}}$ Hajime Matsue, MD, ${ }^{\mathrm{a}}$ Seiki Hamada, MD, ${ }^{\mathrm{b}}$ Tomoyuki Fujita, MD, ${ }^{\mathrm{a}}$ and \\ Yoshiki Sawa, MD, ${ }^{a}$ Osaka, Japan
}

In patients with severe heart failure, mechanical unloading with the use of a left ventricular assist system (LVAS) has been reported to lead to myocardial recovery, which occasionally enables patients to undergo successful device removal. ${ }^{1-3}$ However, there are no conclusive data on how to predict a heart will sufficiently recover because the LVAS imposes a specific situation.

The echocardiographic criteria previously proposed by another group ${ }^{3}$ (left ventricular [LV] diastolic dimension $<$ $55 \mathrm{~mm}, \mathrm{LV}$ ejection fraction $>45 \%$ ) aid in the decision to remove the LVAS. However, because of the severe limitations of heart transplantation, we have adopted more liberal criteria and accepted LV function below these values for LVAS weaning unless the pulmonary capillary wedge pressure increases during the device halt. We think these decision processes are still immature, and we are unable to predict successful weaning.

The recent advance of multidetector computed tomographic angiography (MDCTA) provides various cardiac parameters with high image quality and quantification possibilities in a single image session. ${ }^{4}$ The present study showed our initial experience with MDCTA as an alternative modality for accurate and informative functional analyses in patients receiving the LVAS.

\section{CLINICAL SUMMARY}

The institutional review board approved the study, and patients provided written informed consent. We performed 64-row MDCTA (GE Healthcare, Waukesha, Wis) to assess cardiac function during the off-pump status in 3 patients who underwent LVAS implantation for end-stage dilated cardiomyopathy. At the time of examination, all patients regained a normal range of end-organ function and sinus rhythm. Our routine regimen ${ }^{1}$ to assess myocardial recovery had been carried out before the MDCTA evaluation, and all patients tolerated regular off-pump tests for at least 15 minutes. Base-

\footnotetext{
From the Division of Cardiovascular Surgery, Department of Surgery, ${ }^{\mathrm{a}}$ and Department of Radiology, ${ }^{\mathrm{b}}$ Osaka University Graduate School of Medicine, Osaka, Japan. Received for publication Nov 26, 2007; accepted for publication Feb 2, 2008.

Address for reprints: Goro Matsumiya, MD, Division of Cardiovascular Surgery, Department of Surgery, Osaka University Graduate School of Medicine, 565-0871 2-2

Yamadaoka, Suita, Osaka, Japan (E-mail: matsumg@surg1.med.osaka-u.ac.jp). J Thorac Cardiovasc Surg 2008;136:1602-3

$0022-5223 / \$ 34.00$

Copyright (C) 2008 by The American Association for Thoracic Surgery doi:10.1016/j.jtcvs.2008.02.005
}

line characteristics and the results of regular off-pump tests are shown in Table 1.

Before the image acquisition, the LVAS pump rate was gradually decreased and the device was completely stopped for 10 to 15 minutes after the administration of $3 \mathrm{mg} / \mathrm{kg}$ of heparin. After injection of nonionic contrast of $0.8 \mathrm{~mL} / \mathrm{kg}$, a volume data set of the whole heart (collimation 64 $\times 0.625 \mathrm{~mm}$; gantry rotation time $350 \mathrm{~ms}$; mean scanning time $<10 \mathrm{~s}$ ) was acquired with retrospective electrocardiographic gating. Functional measurements were evaluated using commercially available software (AW Workstation, GE Healthcare). Briefly, a stack of consecutive images (10 phases, each of $5 \mathrm{~mm}$ thickness with a gap of $2 \mathrm{~mm}$ ) was reconstructed in the short-axis of each ventricle. Semiautomated detection of epi- and endocardial borders with manual correction was performed in end diastole and end systole. The software automatically calculated biventricular volumes and ejection fraction.

Image acquisitions were successful without any complications in the patients. The results of functional measurements on MDCTA are shown in Table 2. MDCTA clearly visualized the consecutive change of entire ventricles without any blind area during the cardiac cycle (Figure 1).

\section{DISCUSSION}

It has been reported that the data from MDCTA can be used to assess multiple cardiac functional parameters in patients with heart failure. ${ }^{4}$ As we showed, MDCTA provides precise and informative measurements that are comparable to those measured by conventional modalities, even in patients receiving the LVAS during the temporal device-halt.

Because of the limited donor supply in Japan, we have paid meticulous attention to the use of the LVAS as a "bridge to recovery.", However, reliable criteria to predict successful recovery have not been established. This may reflect the limitations of ultrasound imaging, such as its 2-dimensional nature and suboptimal windows for cardiac measurements. Moreover, the use of the LVAS and the strict anticoagulant therapy preclude assessments of more detailed LV function and other cardiac parameters, such as the right ventricular function by magnetic resonance imaging or routine use of conventional ventriculography. We recently reported detailed analyses about the importance 
TABLE 1. Patients' characteristics and results of regular off-pump test

\begin{tabular}{|c|c|c|c|c|c|c|c|c|c|c|c|}
\hline \multirow[b]{2}{*}{$\begin{array}{c}\text { Patient } \\
\text { No. } \\
\end{array}$} & \multirow[b]{2}{*}{ Age } & \multirow[b]{2}{*}{ Sex } & \multirow[b]{2}{*}{ Diagnosis } & \multirow[b]{2}{*}{ Device } & \multirow{2}{*}{$\begin{array}{l}\text { Duration of LVAD } \\
\text { support } \\
\text { at examination (d) }\end{array}$} & \multicolumn{3}{|c|}{ Echocardiographic data } & \multicolumn{3}{|c|}{ Hemodynamic data } \\
\hline & & & & & & $\begin{array}{r}\text { LVDd } \\
(\mathrm{mm}) \\
\end{array}$ & $\begin{array}{l}\text { LVDs } \\
(\mathrm{mm}) \\
\end{array}$ & $\begin{array}{c}\text { LVEF } \\
(\%) \\
\end{array}$ & $\begin{array}{c}\text { Mean PAP } \\
(\mathrm{mm} \text { Hg) } \\
\end{array}$ & $\begin{array}{c}\text { PCWP } \\
(\mathrm{mm} \mathrm{Hg}) \\
\end{array}$ & $(\mathrm{L} / \mathrm{min})$ \\
\hline 1 & 11 & $\mathrm{~F}$ & IDCM & Toyobo-LV & 82 & 44 & 33 & 51 & 14 & 4 & 3.1 \\
\hline 2 & 55 & M & IDCM & Toyobo-LV & 519 & 47 & 37 & 44 & 8 & 2 & 3.0 \\
\hline 3 & 23 & M & IDCM & Toyobo-LV & 103 & 74 & 65 & 25 & 17 & 9 & 4.5 \\
\hline
\end{tabular}

$I D C M$, Idiopathic dilated cardiomyopathy; Toyobo- $L V$, Toyobo-NCVC (National CardioVascular Center) with apical drainage; $L V D d$, left ventricular end-diastolic diameter; $L V D$ s, left ventricular end-systolic diameter; $L V E F$, left ventricular ejection fraction; $P A P$, pulmonary artery pressure; $P C W P$, pulmonary capillary wedge pressure; $C O$, cardiac output.

TABLE 2. Cardiac measurements on multidetector computed tomographic angiography and outcomes

\begin{tabular}{lcccccccccc}
\hline $\begin{array}{l}\text { Patient } \\
\text { No. }\end{array}$ & $\begin{array}{c}\text { Heart rate } \\
(\text { beats/min) }\end{array}$ & $\begin{array}{c}\text { LVEDV } \\
(\mathbf{m L})\end{array}$ & $\begin{array}{c}\text { LVESV } \\
(\mathbf{m L})\end{array}$ & $\begin{array}{c}\text { LVEF } \\
(\%)\end{array}$ & $\begin{array}{c}\text { SV } \\
(\mathbf{m L})\end{array}$ & $\begin{array}{c}\text { CO } \\
(\mathbf{L} / \mathbf{m i n})\end{array}$ & $\begin{array}{c}\text { RVEDV } \\
(\mathbf{m L})\end{array}$ & $\begin{array}{c}\text { RVESV } \\
(\mathbf{m L})\end{array}$ & $\begin{array}{c}\text { RVEF } \\
(\%)\end{array}$ & \begin{tabular}{c} 
Outcome \\
\hline 1
\end{tabular} \\
\hline & 79 & 82 & 45 & 45 & 37 & 2.8 & 134 & 104 & 22 & Explantation \\
2 & 60 & 123 & 63 & 49 & 60 & 3.6 & 110 & 68 & 38 & Explantation \\
3 & 71 & 301 & 243 & 19 & 58 & 4.1 & 175 & 143 & 19 & Ongoing \\
\hline
\end{tabular}

$L V E D V$, Left ventricular end-diastolic volume; $L V E S V$, left ventricular end-systolic volume; $L V E F$, left ventricular ejection fraction; $S V$, stroke volume; $C O$, cardiac output; $R V E D V$, right ventricular end-diastolic volume; $R V E S V$, right ventricular end-systolic volume; $R V E F$, right ventricular ejection fraction.

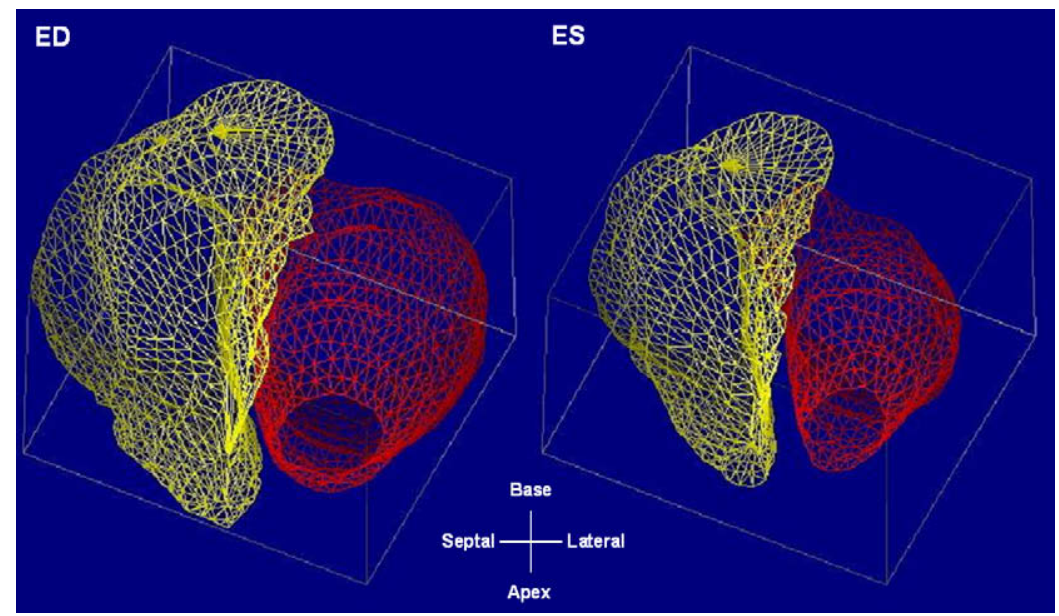

FIGURE 1. Three-dimensional reconstructive images of left (red wire mesh) and right (yellow wire mesh) ventricular endocardial surfaces in case 2. $E D$, End diastole; $E S$, end systole.

of echocardiographic measurements and hemodynamic changes during the off-pump test (Goro Matsumiya, MD. The $43^{\text {rd }}$ Annual Meeting of the Society of Thoracic Surgeons, in 2007). Utility parameters derived from a noninvasive and accurate imaging tool are desirable to determine the device removal.

Although future studies are still required, we think that further experience using MDCTA will have an impact on the assessment of myocardial recovery in patients with an LVAS. This newer modality provides various cardiac measurements easily and precisely without the use of invasive approaches in a single image session.

\section{LIMITATIONS}

As found in other conventional modalities, there are inherent limitations of MDCTA, including the need for con- trast medium and radiation exposure. The effective radiation dose of MDCTA was 11 to $18 \mathrm{mSv}$ in our patients, which was higher than that of conventional angiography. These factors must be taken into account, and MDCTA should not be used in all patients.

\section{References}

1. Matsumiya G, Monta O, Fukushima N, Sawa Y, Funatsu T, Toda K, et al Who would be a candidate for bridge to recovery during prolonged mechanical left ventricular support in idiopathic dilated cardiomyopathy? J Thorac Cardiovasc Surg. 2005;130:699-704.

2. Birks EJ, Tansley PD, Hardy J, George RS, Bowles CT, Burke M, et al. Left ventricular assist device and drug therapy for the reversal of heart failure. $N$ Engl J Med. 2006;355:1873-84.

3. Dandel M, Weng Y, Siniawski H, Potapov E, Lehmkuhl HB, Hetzer R. Long-term results in patients with idiopathic dilated cardiomyopathy after weaning from left ventricular assist devices. Circulation. 2005;112(suppl I):I-37-45.

4. Butler J. The emergent role of multi-detector computed tomography in heart failure. J Card Fail. 2007;13:215-26. 